Technological University Dublin ARROW@TU Dublin

2005-01-01

\title{
New insights into bile acid amidation
}

\author{
Mary Hunt \\ Technological University Dublin, mary.hunt@tudublin.ie \\ Eithne O'Shea \\ Karolinska Institute \\ Karianne Solaas \\ Rikshospitalet, Norway
}

See next page for additional authors

Follow this and additional works at: https://arrow.tudublin.ie/scschbioart

Part of the Molecular Biology Commons

\section{Recommended Citation}

Hunt, M., O'Shea, E.,Solaas,K., Kase, B., Alexson,S.New insights into bile acid amidation In Proceedings of 'Biology of bile acids in health and disease', XVI International Bile Acid Meeting. Kluwer Academic Publishers doi: $10.21427 /$ qtsc-q846

This Book Chapter is brought to you for free and open access by the School of Biological Sciences at ARROW@TU Dublin. It has been accepted for inclusion in Articles by an authorized administrator of ARROW@TU Dublin. For more information, please contact arrow.admin@tudublin.ie, aisling.coyne@tudublin.ie, gerard.connolly@tudublin.ie.

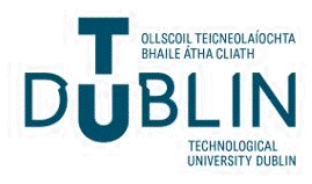


Authors

Mary Hunt, Eithne O'Shea, Karianne Solaas, Bengt Kase, and Stefan Alexson

This book chapter is available at ARROW@TU Dublin: https://arrow.tudublin.ie/scschbioart/48 
New insights into bile acid amidation.

\section{Mary C. Hunt, Ethna O'Shea, *Karianne Solaas, *Bengt Frode Kase and Stefan E. H. Alexson.}

Karolinska Institutet, Department of Laboratory Medicine, Division of Clinical Chemistry, Karolinska University Hospital at Huddinge, SE-141 86 Stockholm, Sweden and *Department of Pediatric Research, Rikshospitalet, NO-0027 Oslo, Norway.

Address for correspondence:

Mary Hunt

Karolinska Institutet

Division of Clinical Chemistry C1-74

Karolinska University Hospital at Huddinge Phone: +46-8-58581293

SE-141 86 Stockholm

Fax: $+46-8-58581260$

Sweden

Email:mary.hunt@labmed.ki.se 


\section{Introduction}

De-novo bile acid (BA) formation is the major pathway in mammals for excretion of cholesterol (for review, see [1]). BAs are synthesized from cholesterol in the liver and are conjugated to either glycine or taurine before secretion into the bile. This conjugation (or amidation) plays several important biological roles: it promotes secretion of BAs and cholesterol into bile, and increases the detergent properties of BAs in the intestine, which facilitates lipid and vitamin absorption. BAs are deconjugated by the intestinal flora and recycled back to the liver for reconjugation. The initial steps in the biosynthesis of BAs involve oxidative modifications of the cholesterol backbone and side-chain to form dihydroxycholestanoic acid (DHCA) and trihydroxycholestanoic acid (THCA). DHCA and THCA are activated to their corresponding CoA-esters, followed by $\square$-oxidative cleavage in peroxisomes to form chenodeoxycholoyl-CoA (CDCA-CoA) and choloyl-CoA (CA-CoA) respectively, which are substrates for conjugation to glycine or taurine [2-5]. This conjugation (or amidation) is catalyzed by the enzyme bile acid-CoA:amino acid $N$ acyltransferase (BACAT), an enzyme recently implicated in inheritance of familial hypercholanemia [6]. Recent data show that BACAT activity is present both in peroxisomes and in cytosol [5], suggesting the existence of two BACAT enzymes. It has been proposed that while the peroxisomal enzyme conjugates de-novo synthesized BAs, the cytosolic enzyme has a function in conjugating BAs recycled from the intestine via the enterohepatic circulation to the liver. Mihalik et al also recently suggested the existence of two pathways for conjugation of BAs. They showed that human very long-chain acyl-CoA synthetase (VLCS), present in peroxisomes and the endoplasmic reticulum, primarily activates THCA, which is a precursor for de-novo synthesis of bile acids. In contrast, a homologue of this enzyme (VLCS-H2) located in the endoplasmic reticulum and referred to as bile acid-CoA synthetase (BACS), activates mainly BAs [7]. It was therefore suggested that BACS activates recycled BAs for conjugation by BACAT in the cytosol. However, to date only one BACAT enzyme has been identified and characterized. The enzyme has been purified from several species such as rat [8], bovine [9], domestic fowl [10], fish [11] and human [12], and partially purified from pig [13], canine [14], guinea pig and rabbit [15]. Molecular cloning of the human BACAT showed that the enzyme can conjugate bile acids to both glycine and taurine [16]. 
Recently it has been shown that recombinantly expressed human BACAT can also conjugate fatty acyl-CoAs to glycine [17].

We have recently identified and characterized a family of highly homologous acylCoA thioesterases, referred to as type-I acyl-CoA thioesterases, with putative localizations in peroxisomes (PTE-Ia, PTE-Ib and PTE-Ic), mitochondria (MTE-I) and cytosol (CTE-I) [18, 19]. Database searches and subsequent sequence alignments revealed that these acyl-CoA thioesterases show sequence homology only to BACAT from rat [20], mouse [21] and human [16], with a sequence identity of $40-45 \%$ to the type-I acyl-CoA thioesterases. Acyl-CoA thioesterases hydrolyze acyl-CoAs to non-esterified fatty acids and CoASH. By preserving a balance of acyl-CoA, free fatty acids and CoASH in the cell, acyl-CoA thioesterases directly, and indirectly via gene regulation, influence numerous cellular processes involved in lipid metabolism, for example $\square$-oxidation and esterification of fatty acids (for review, see [22]).

We have now identified two new enzymes related to both BACAT and the type-I acyl-CoA thioesterases. These gene products show approximately 55\% sequence identity to the mouse BACAT and approximately 95\% sequence identity to eachother. Both these proteins contain a peroxisomal type-I targeting signal of SKL, which targets the proteins to peroxisomes. We suggest that one of these proteins could be a novel peroxisomal BACAT.

\section{Experimental procedures}

\section{Preparation and characterization of mouse liver subcellular fractions}

Homogenates were prepared from SV/129 male mouse fresh liver as described [23]. Purified peroxisomes were isolated by density gradient centrifugation of light-mitochondrial fractions prepared from homogenates of pooled livers from untreated and WY-14,643 treated mice as described [24]. Bile acid-CoA:amino acid $N$-acyltransferase activity was measured as previously described (3).

\section{Antibody production and affinity purification}

A peptide with the amino acid sequence $\mathrm{NH}_{2}$-CAAQEHSWKEIQKFLK-COOH, based on the mouse BACAT amino acid sequence [25], (with a cysteine added at the $\mathrm{NH}_{2}$-terminal end for coupling of the peptide) was synthesized and used to 
raise antisera in rabbits (Sigma Genosys). The BACAT antibody was purified from rabbit serum using a peptide affinity column prior to Western blotting.

\section{Western blot analysis}

Western blot analysis was performed as described previously [26] using the BACAT antibody and a horseradish peroxidase conjugated anti-rabbit IgG secondary antibody. The signal was detected using enhanced chemiluminescence (ECL) (Amersham Life Science, Arlington Heights, IL) and the filters were exposed to X-ray film.

\section{Northern blot analysis}

Total RNA was prepared from mouse livers using QuickPrep ${ }^{\mathrm{R}}$ total RNA extraction kit (Amersham Pharmacia Biotech, Uppsala, Sweden), and Northern blot analysis was carried out as described previously [26]. The filter was probed with a ${ }^{32} \mathrm{P}$-labelled full-length cDNA probe for the newly identified mouse peroxisomal BACAT and the blot was exposed to X-ray film at $-70^{\circ} \mathrm{C}$.

\section{Localization of mouse BACAT using green fluorescent fusion protein (GFP) -} The mouse BACAT open reading frame [25] was cloned into the pcDNA3.1/NTGFP vector (Invitrogen), in-frame with the GFP at the N-terminal end. Sitedirected mutagenesis was carried out using the QuikChange $\square$ Site Directed Mutagenesis kit (Stratagene), to mutate the C-terminal -SQL to -SKL. The nucleotide change was verified by sequencing. The open reading frame of one of the newly identified peroxisomal BACAT enzymes, ending -SKL, was cloned inframe into the pcDNA3.1/NT-GFP vector (Invitrogen) with the GFP at the Nterminal end. Human skin fibroblasts from a healthy control and a Zellweger patient were grown as described [27]. Fibroblasts were transfected with $10 \square \mathrm{g}$ of BACAT/NT-GFP plasmids using Calcium Phosphate method as described, but without staining of the nucleus with Hoescht 33342 [27].

\section{Results}

\section{Mouse BACAT is regulated by treatment with WY-14,643}

BACAT activity was measured in both cytosolic and peroxisomal fractions from both untreated mouse liver and those treated with the peroxisome proliferator 
WY-14,643. In the cytosolic fraction, BACAT activity was approximately 20 $\mathrm{nmol} / \mathrm{min} / \mathrm{mg}$ and was unchanged by treatment with WY-14,643 (Fig. 1A). However, in peroxisomal fractions, the specific activity of BACAT was approximately $100 \mathrm{nmol} / \mathrm{min} / \mathrm{mg}$ and was reduced to approximately 7 $\mathrm{nmol} / \mathrm{min} / \mathrm{mg}$ following treatment with WY-14,643. Western blot analysis using an antibody to the C-terminal end of the published mouse BACAT [25] showed that the BACAT protein in cytosol was also unchanged following WY-14,643 treatment, however in peroxisomes, BACAT protein was severely decreased following WY-14,643 treatment (Fig. 1B). This suggested the existence of two distinct BACAT enzymes, one in cytosol, which is not regulated by fibrate treatment, and one in peroxisomes that is highly downregulated via fibrates.

\section{Mouse BACAT is a cytosolic enzyme}

The human and mouse BACAT enzymes previously cloned [25, 28] contain a Cterminal -SQL which is a variant of the well-characterized consensus peroxisomal type-1 targeting signal (PTS1) of -SKL (serine, lysine, leucine), the latter which has been shown to target proteins to peroxisomes [29]. To establish whether BACAT is localized in peroxisomes, we cloned the mouse BACAT in-frame with GFP at the N-terminal end, which leaves the C-terminal -SQL sequence accessible. The plasmid encoding the mouse BACAT-GFP fusion protein was transfected into human skin fibroblasts, and by using immunofluorescence microscopy for detection of a Tritc labelled anti-GFP antibody, mouse BACAT showed a diffuse GFP expression, with no sign of a punctate pattern, indicative of a cytosolic localization (Fig. 2A). We also mutated the C-terminal -SQL to -SKL, the consensus PTS1 targeting signal, and transfected this construct into human skin fibroblasts. Immunofluorescence microscopy showed that the mouse BACAT-SKL mutant was translocated to peroxisomes based on the punctate pattern (Fig. 2B). Similar results were obtained by transfection of the human BACAT-GFP fusion plasmid [17].

\section{Identification of new candidate genes for peroxisomal BACAT}

Database searches were carried out using the open reading frame for the mouse BACAT [25] and type-I acyl-CoA thioesterases [18] (www.ncbi.nih.gov). Two candidate genes were identified, one of which is localized on the same 
chromosome as the mouse BACAT previously cloned, mouse chromosome 4. These gene products encode proteins of approximately $46 \mathrm{kDa}$, and show about $55 \%$ sequence identity to the mouse BACAT. The 2 newly identified putative BACAT enzymes show approximately 95\% sequence identity to eachother.

\section{Characterization of the new peroxisomal BACAT enzymes}

The putative peroxisomal BACAT enzymes both contain an -SKL at their carboxyterminal ends, which should result in localization of these proteins in peroxisomes. To establish whether one of these BACAT proteins is localized in peroxisomes, we cloned the putative peroxisomal BACAT in-frame with GFP at the N-terminal end, which leaves the C-terminal -SKL sequence accessible. The GFP fusion protein plasmid was transfected into human skin fibroblasts from a control and a Zellweger patient, who are unable to import peroxisomal matrix proteins. Using immunofluorescence microscopy for detection of a Tritc labelled anti-GFP antibody, the peroxisomal BACAT showed a distinct punctate pattern of expression, indicative of a peroxisomal localization (Fig. 3A). In Zellweger fibroblasts, the GFP fusion protein showed a diffuse GFP expression, with little sign of a punctate pattern, indicative of a cytosolic localization (Fig. 3B)

Northern blot analysis using a full-length probe to one of the newly identified putative peroxisomal BACAT enzymes (which will recognize both peroxisomal BACAT transcripts due to the very high degree of sequence identity to eachother $(95 \%))$ showed that these enzymes are mainly expressed in liver, kidney and gallbladder, with one of these enzymes also weakly expressed in proximal and distal intestine and spleen (Fig. 4).

\section{Discussion}

There are two pathways for conjugation of bile acids to glycine or taurine in the cell. BACAT activity is present in peroxisomes for amidation (conjugation) of denovo synthesized bile acids, while a cytosolic BACAT enzyme functions in amidation of recycled bile acids [5]. The specific BACAT activity from human [5] and mouse liver [24] is much higher in the peroxisomal fraction compared to the

cytosolic fraction. Based on the findings that BACAT is mainly cytosolic in mouse 
(this study) and human [17], it is proposed that the function of the previously characterized BACAT is in the conjugation of recycled bile acids, and it was predicted that there exists another peroxisomal BACAT enzyme that conjugates de-novo synthesized bile acids. Conjugation of bile acids is believed to occur mainly in the liver. In mouse, the cytosolic BACAT enzyme is strongly expressed in liver, gallbladder and intestine (both proximal and distal), compatible with an important function in amidation of bile acids and protection of gastro-intestinal mucosal cells from accumulation of free bile acids [17]. Recycled free bile acids need to be activated to the corresponding CoA-ester prior to conjugation to glycine or taurine by the BACAT enzyme. Recent studies have shown that bile acids are mainly activated by BACS, a microsomal bile acid-CoA synthetase, while THCA, a precursor of de-novo bile acid synthesis in peroxisomes, is mainly activated by very long-chain acyl-CoA synthetase (VLCS) located in the peroxisomal and endoplasmic reticulum membranes [7, 30]. Pircher et al have now shown that both BACAT and BACS are target genes of the farnesoid X receptor (FXR), the key nuclear receptor involved in regulation of bile acid sythnesis, consolidating their function in conjugation of bile acids [31].

There has been some controversy during the past years concerning the subcellular localization of BACAT. Experiments carried out on homogenates from frozen human liver showed BACAT to be cytosolic, although it was suggested that freezing and thawing of the liver may have caused lysis of cellular organelles leading to a redistribution of BACAT activity from the peroxisomes to the cytosol [13]. Immunohistochemical analysis showed that BACAT was localized in the cytoplasm of hepatocellular carcinoma cells as well as the hepatocytes and the bile duct cells in human liver [32]. More recently it has been shown that BACAT activity is present both in cytosolic and peroxisomal fractions [5]. Although both the human and mouse BACAT proteins contain a variant (-SQL) $[16,25]$ of the type I peroxisomal targeting signal (PTS1) -SKL, our data shows that the mouse BACAT protein is mainly cytosolic. Mutation of the -SQL sequence to -SKL results in the translocation of the protein from the cytosol, exclusively to peroxisomes. The human BACAT also shows a cytosolic localization and mutation of the -SQL to -SKL results in a peroxisomal localization [17]. Therefore the previously cloned mouse [25] and human [28] BACAT enzymes are cytosolic, which suggests that there exists a further peroxisomal BACAT responsible for the conjugation of denovo synthesized bile acids in peroxisomes. 
Recent data from Inoue et al [33] further supported the hypothesis for a second peroxisomal BACAT enzyme, using the null mouse model of the hepatocyte nuclear factor $4 \square$ (HNF-4 $)$. The HNF-4 is a nuclear receptor that has an important role in regulating expression of many liver-specific genes. In the HNF$4 \square$-null mouse model, expression of BACAT is almost undetectable in mouse liver using Northern blot analysis, suggesting that this receptor has an important function in maintaining expression of BACAT. A HNF- $4 \square$ binding site was indeed demonstrated in the promotor of the BACAT gene [33]. These animals showed an altered bile acid pattern with increased unconjugated bile acids in serum. They also showed an increase in glycine-conjugated bile acids. It has been shown that the mouse BACAT does not contain glycine conjugating activity [25], therefore this suggested that there may be a further unidentified BACAT gene which is activated in the HNF-4 $\square$-null mouse model, and which can conjugate bile acids to glycine.

\section{Identification of a putative new peroxisomal BACAT}

BACAT shows approximately $40-45 \%$ sequence identity to a family of enzymes known as acyl-CoA thioesterases. These enzymes have been identified in several cellular compartments such as cytosol, mitochondria and peroxisomes (for review see [22]. Database searches using both BACAT and acyl-CoA thioesterase sequences, identified two further genes in mouse which are related to both BACAT and acyl-CoA thioesterases. The products of these two genes show approximately 55\% sequence identity to BACAT and are expressed in liver, kidney, gallbladder and weakly in proximal and distal intestine. Both these enzymes contain the classical peroxisomal type I targeting signal of -SKL at their carboxyterminal ends, which targets the proteins to peroxisomes. We therefore suggest that one of these enzymes could be the new candidate peroxisomal BACAT. We are currently expressing these gene products as recombinant proteins to examine if they have bile acid conjugating activity. However, we have encountered problems to obtain soluble protein in E. coli, but are currently working on other expression systems.

In conclusion, we have provided evidence for a novel peroxisomal BACAT, which may conjugate de-novo synthesized bile acids in peroxisomes. 


\section{Figure legends}

Fig. 1: Differential regulation of peroxisomal and cytosolic BACAT activity and protein following treatment with WY-14,643. (A) Cytosol and purified peroxiomes were isolated from pooled livers from untreated (black bars) and WY-14,643 treated (grey bars) mice. BACAT activity was measured in each fraction as described in Experimental Procedures. Fig. adapted from [24]. (B) Western blot analysis of protein isolated from cytosol (38 $\mathrm{Dg}$ ) or purified peroxisomes $(5 \square \mathrm{g})$ from control (untreated) or WY-14,643 treated mouse liver, using an affinity purified antibody to mouse BACAT.

Fig. 2: Mouse BACAT is localized in cytosol. The previously cloned mouse BACAT [25] was expressed as a green fluorescent fusion protein (with the Cterminal sequence-SQL) and the same plasmid mutated in the C-terminal to -SKL. Human skin fibroblasts were transfected with these BACAT-GFP plasmids and the cells were incubated with a rabbit GFP antibody followed by a CY3 conjugated affinity purified donkey anti-rabbit IgG and examined by immunofluorescence microscopy. A; mouse BACAT (-SQL), B; mouse BACATSKL mutant.

Fig. 3: The newly identified peroxisomal BACAT is localized in peroxisomes. The open reading frame of the putative peroxisomal BACAT was cloned as a green fluorescent fusion protein and human skin fibroblasts from a healthy control and a Zellweger patient were transfected with this plasmid. The cells were incubated with a rabbit GFP antibody followed by a CY3 conjugated affinity purified donkey anti-rabbit IgG and examined by immunofluorescence microscopy. (A) Control fibroblasts (B) Zellweger fibroblasts.

Fig. 4: Tissue expression of peroxisomal BACAT. Northern blot analysis was carried out on $20 \square \mathrm{g}$ of total RNA from SV / 129 male mouse tissues. The filter was incubated with a ${ }^{32} \mathrm{P}$-labelled mouse peroxisomal BACAT cDNA probe as described in Experimental Procedures. BAT: brown adipose tissue, WAT: white adipose tissue. 
Acknowledgements: This work was supported by The Swedish Research Council, Hjärt-Lungfonden, Svenska Sällskapet för Medicinsk Forskning, Lars Hiertas

Minne, Fredrik och Ingrid Thurings Stiftelse, Ruth och Richard Julins Stiftelse and National Network for Cardiovascular Research (Sweden).

\section{References}

1. Russell, D. W. (2003) The enzymes, regulation, and genetics of bile acid synthesis., Аnпи. Rev. Biochem. 72, 137-174.

2. Kase, F., Björkhem, I., Pedersen, J. I. (1983) Formation of cholic acid from 3-alpha, 7alpha, 12-alpha-trihydroxy-5-beta-cholestanoic acid by rat liver peroxisomes, J. Lipid Res. 24, 1560-1567.

3. Kase, B. F., Prydz, K., Björkhem, I., Pedersen, J. I. (1986) In vitro formation of bile acids from di- and trihydroxy-5-beta-cholestanoic acid in human liver peroxisomes, Biochim. Biophys. Acta. 877, 37-42.

4. Kase, B. F., Björkhem, I. (1989) Peroxisomal bile acid-CoA:amino-acid Nacyltransferase in rat liver, J. Biol. Chem. 264, 9220-9223.

5. Solaas, K., Ulvestad, A., Söreide, O., Kase, B. F. (2000) Subcellular organisation of bile acid amidation in human liver: a key issue in regulating the biosynthesis of bile salts, J. Lipid Res. 41, 1154-1162.

6. Carlton, V. E. H., Harris, B. Z., Puffenberger, E. G., Batta, A. K., Knisely, A. S., Robinson, D. I., Strauss, K. A., Shneider, B. L., Lim, W. A., Salen, G., Holmes Morton, D. \& Bull, L. N. (2003) Complex inheritance of familial hypercholanemia with associated mutations in TJP2 and BAAT., Nature genetics. 34, 91-96.

7. Mihalik, S. J., Steinberg, S. J., Pei, Z., Park, J., Kim, D. G., Heinzer, A. K., Dacremont, G., Wanders, R. J. A., Cuebas, D. A., Smith, K. D., Watkins, P. A. (2002) Participation of two members of the very long-chain acyl-CoA synthetase family in bile acid synthesis and recycling., J. Biol. Chem. 277, 24771-24779.

8. Killenberg, P. G., Jordan, J. T. (1978) Purification and characterisation of bile acidCoA:amino acid N-acyltransferase from rat liver, J. Biol. Chem. 253, 10005-1010.

9. Vessey, D. A. (1979) The co-purification and common identity of cholyl CoA:glycineand cholyl CoA:taurine-N-acyltransferase activities from bovine liver, J. Biol. Chem. 254, 2059-2063.

10. Czuba, B., Vessey, D. A. (1981) Purification and characterization of cholyl-CoA: taurine $\mathrm{N}$-acetyltransferase from the liver of domestic fowl (Gallus gallus), Biochem. $J$. 195, 263-266.

11. Vessey, D. A., Benfatto, A. M., Zerweck, E., Vestweber, C. (1990) Purification and characterization of the enzymes of bile acid conjugation from fish liver, Comp. Biochem. Physiol. 95B, 647-652. 
12. Johnson, M. R., Barnes, S., Kwakye, J. B., Diasio, R. B. (1991) Purification and characterization of bile acid-CoA: amino acid N-acyltransferase from human liver, J. Biol. Chem. 266, 10227-10233.

13. Kwakye, J. B., Johnson, M. R., Barnes, S., Diasio, R. B. (1991) A comparative study of bile acid CoA:amino acid:N-acyltransferase (BAT) from four mammalian species, Comp. Biochem. Physiol. 100B, 131-136.

14. Czuba, B., Vessey, D. A. (1981) Identification of a unique mammalian species of cholyl-CoA: amino acid N-acyltransferase, Biochim. Biophys. Acta. 665, 612-614.

15. Vessey, D. A. (1978) The biochmedical basis for the conjugation of bile acids with either glycine or taurine, Biochem. J. 174, 621-626.

16. Falany, C. N., Johnson, M. R., Barnes, S., Diasio, R. B. (1994) Glycine and taurine conjugation of bile acids by a single enzyme, J. Biol. Chem. 269, 19375-19379.

17. O'Byrne, J., Hunt, M. C., Rai, D. K., Saeki, M. \& Alexson, S. E. H. (2003) The human bile acid-CoA:amino acid N-acyltransferase functions in conjugation of fatty acids to glycine., J. Biol. Chem. 278, 34237-34344.

18. Hunt, M. C., Nousiainen, S. E. B., Huttunen, M. K., Orii, K. E., Svensson, L. T., Alexson, S. E. H. (1999) Peroxisome proliferator-induced long chain acyl-CoA thioesterases comprise a highly conserved novel multi-gene family involved in lipid metabolism, J. Biol. Chem. 274, 34317-34326.

19. Westin, M. A., Alexson, S. E. H. \& Hunt, M. C. (2004) Molecular cloning and characterization of two mouse peroxisome proliferator-activated receptor alpha (PPARalpha)-regulated peroxisomal acyl-CoA thioesterases., J. Biol. Chem. 279, 2184121848.

20. Furutani, M., Arii, S., Higashitsuji, H., Mise, M., Fukumoto, M., Takano, S., Nakayama, H., Imamura, M., Fujita, J. (1995) Reduced expression of Kan-1 (encoding putative bile acid-CoA:amino acid $\mathrm{N}$-acyltransferase) mRNA in livers of rats after partial hepatectomy and during sepsis, Biochem. J. 311, 203-208.

21. Falany, C. N., Fortinberry, H., Leiter, E. H., Barnes, S. (1997) Cloning, expression, and chromosomal localization of mouse liver bile acid-CoA:amino acid $\mathrm{N}$-acyltransferase, J. Biol. Chem. 38, 1139-1148.

22. Hunt, M. C., Alexson, S. E.H. (2002) The role acyl-CoA thioesterases play in mediating intracellular lipid metabolism, Prog. Lipid Res. 41, 99-130.

23. Prydz, K., Kase, B. F., Björkhem, I. \& Pedersen, J. I. (1986) Formation of chenodeoxycholic acid from 3alpha,7alpha-dihydroxy-5beta-cholestanoic acid by rat liver peroxisomes., J. Lipid Res. 27, 622-628.

24. Solaas, K., Kase, B. F., Pham, V., Bamberg, K., Hunt, M. C. \& Alexson, S. E. H. (2004) Differential regulation of cytosolic and peroxisomal bile acid amidation in mouse liver: PPAR alpha activation favors formation of unconjugated bile acids., J. Lipid Res. 45, 1051-1060.

25. Falany, C. N., Fortinberry, H., Leiter, E. H. \& Barnes, S. (1997) Cloning, expression, and chromosomal localization of moue liver bile acid-CoA:amino acid $\mathrm{N}$-acyltransferase., J. Lipid Res. 38, 1139-1148.

26. Hunt, M. C., Lindquist, P. J. G., Peters, J. M., Gonzalez, F. J., Diczfalusy, U. \& Alexson, S. E. H. (2000) Involvement of the peroxisome proliferator-activated receptor alpha (PPAR $\square$ ) in regulation of long chain acyl-CoA thioesterases, J. Lipid Res. 41, 814823. 
27. Hunt, M. C., Solaas, K., Kase, B. F., Alexson, S. E. H. (2002) Characterization of an acyl-CoA thioesterase that functions as a major regulator of peroxisomal lipid metabolism, J. Biol. Chem. 277, 1128-1138.

28. Falany, C. N., Johnson, M. R., Barnes, S. \& Diasio, R. B. (1994) Glycine and taurine conjugation of bile acids by a single enzyme. Molecular cloning and expression of human liver bile acid-CoA:amino acid N-acyltransferase., J. Biol. Chem. 269, 19375-19379. 29. Gould, S. J., Keller, G. A., Hosken, N., Wilkinson, J. \& Subramani, S. (1989) A conserved tripeptide sorts proteins to peroxisomes, J. Cell. Biol. 108, 1657-1664.

30. Steinberg, S. J., Mihalik, S. J., Kim, D. G., Cuebas, D. A., Watkins, P. A. (2000) The human liver-specific homolog of very long-chain acyl-CoA synthetase is cholate:CoA ligase, J. Biol. Chem. 275, 15605-15608.

31. Pircher, P. C., Kitto, J. L., Petrowski, M. L., Tangirala, R. K., Bischoff, E. D., Schulman, J. G. \& Westin, S. K. (2003) Farnexoid X receptor regulates bile acid-amino acid conjugation, J. Biol. Chem. 278, 27703-27711.

32. Furutani, M., Arii, S., Higashitsuji, H., Mise, M., Fukumoto, M., Takano, S., Nakayama, H., Imamura, M. \& Fujita, J. (1995) Reduced expression of kan-1 (encoding putative bile acid-CoA-amino acid $\mathrm{N}$-acyltransferase) mRNA in livers of rats after partial hepatectomy and during sepsis, Biochem. J. 311, 203-208.

33. Inoue, Y., Ai-Ming, Y., Inoue, J. \& Gonzalez, F. (2004) Hepatocyte nuclear factor 4 is a central regulator of bile acid conjugation, J. Biol. Chem. 279, 2480-2489. 
Fig. 1

A

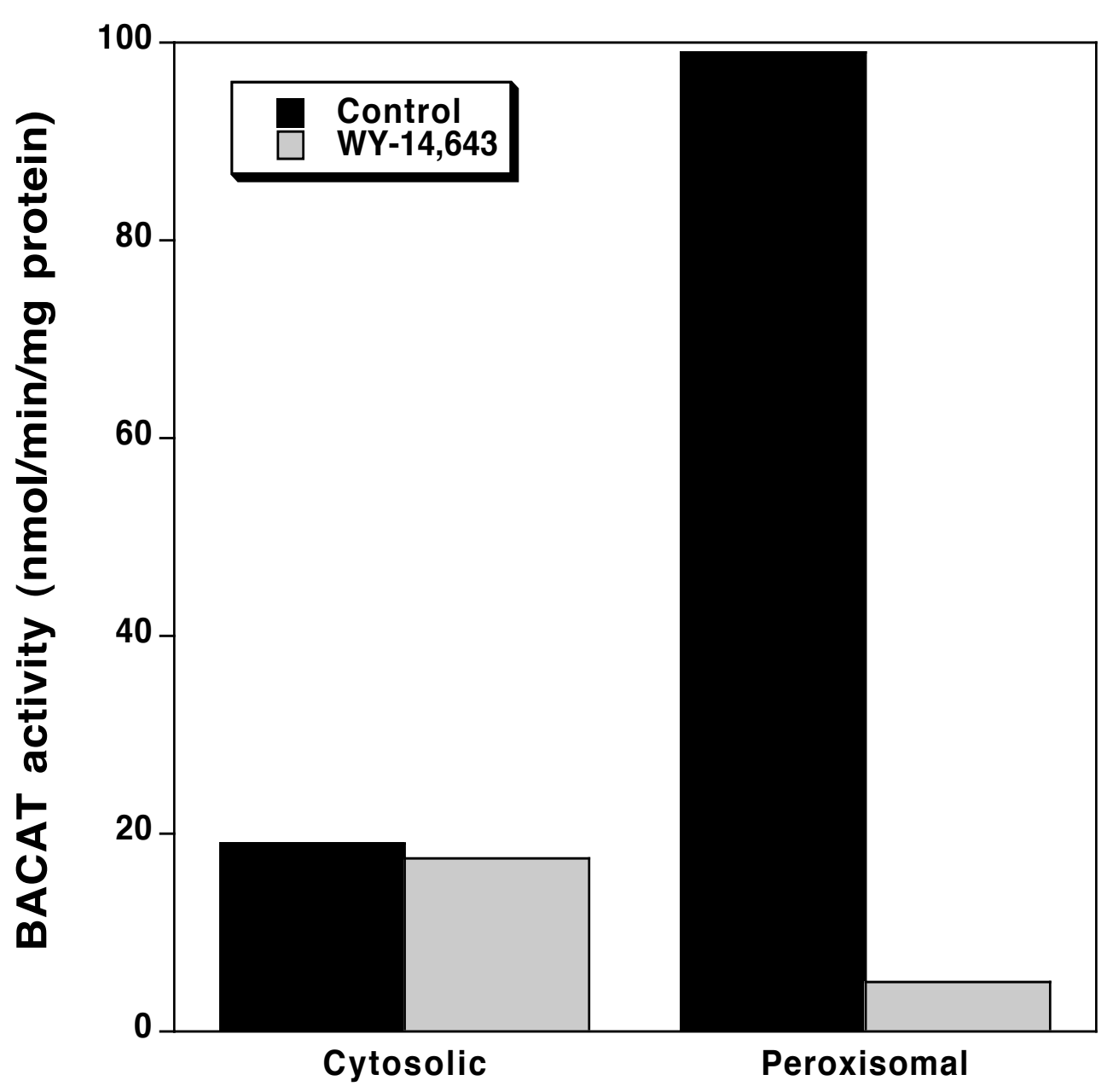

Fraction 
Fig. 1

B

\section{Cytosol Peroxisomes}

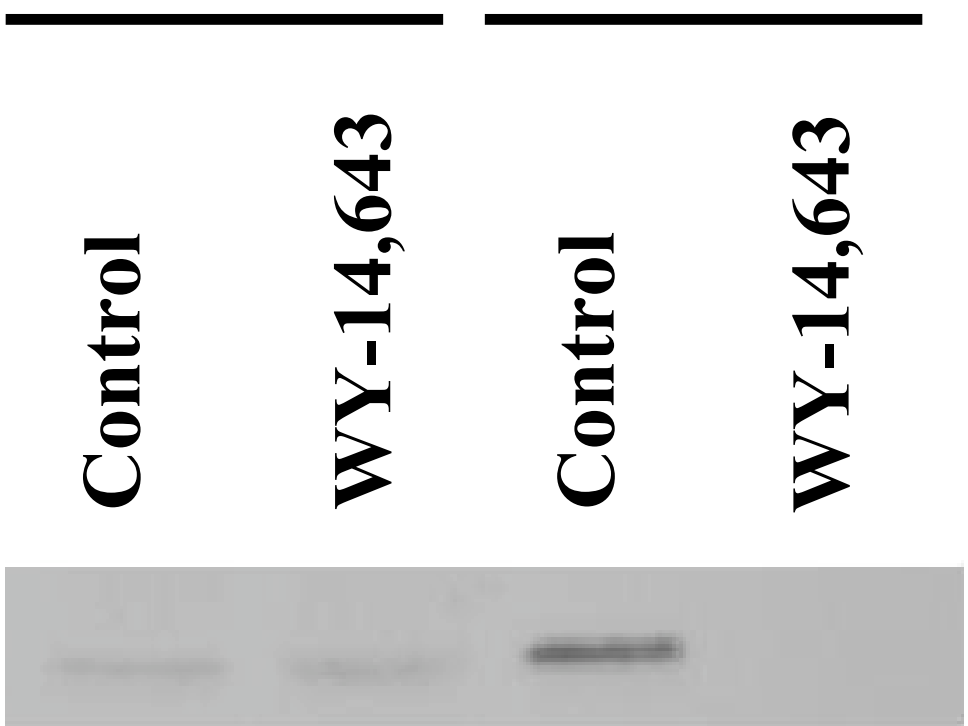


Fig. 2

A

B
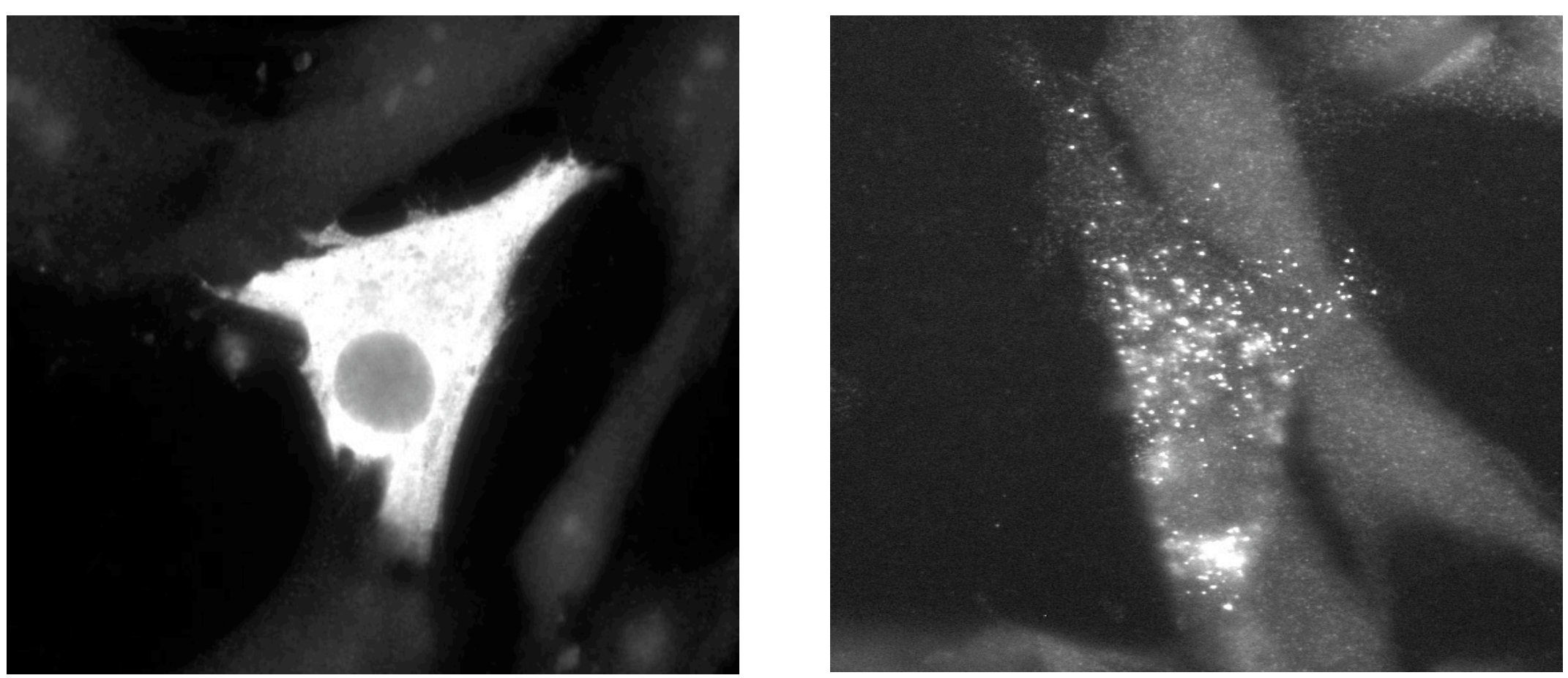
Fig. 3

A

B
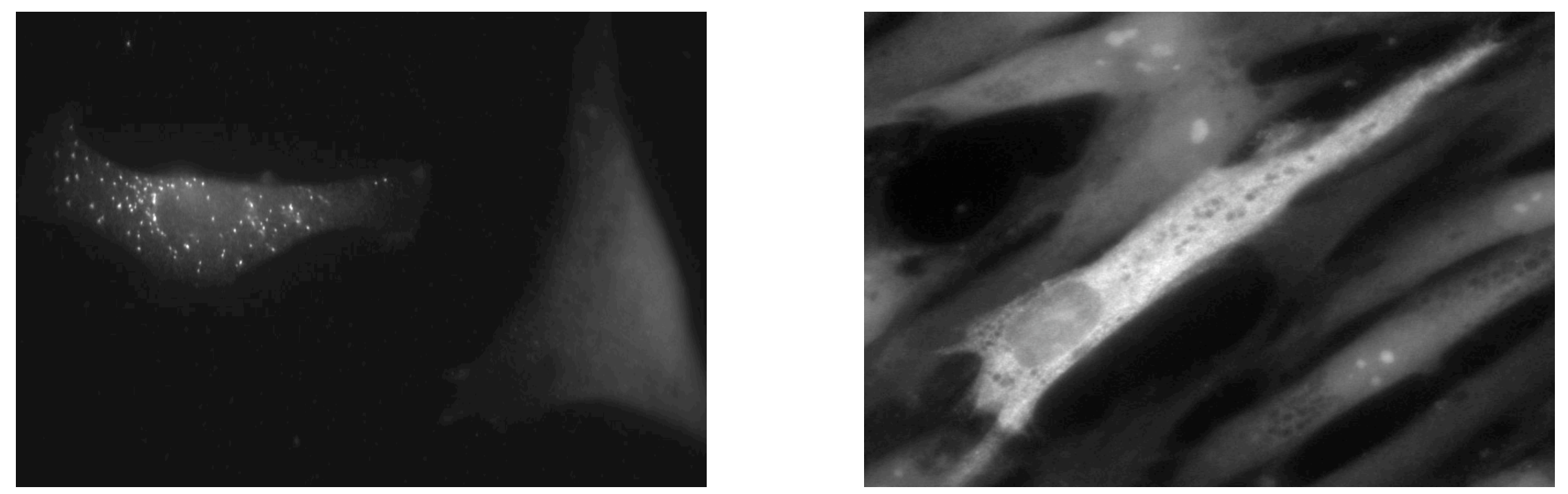
Fig. 4

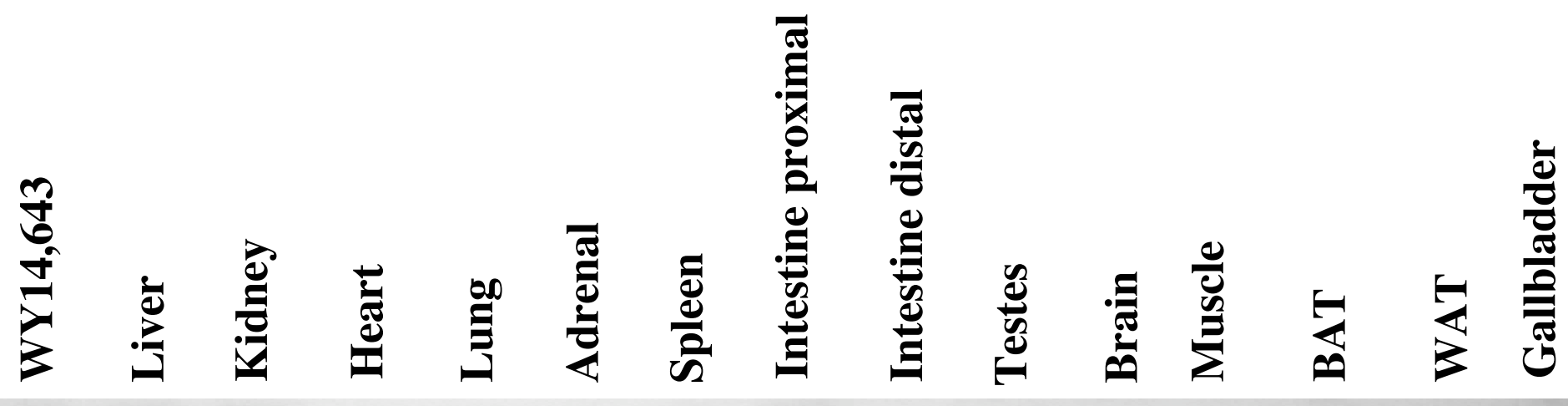

pBACAT

$5.5 \mathrm{~Kb}$

$2.2 \mathrm{~Kb}$ 